\title{
Toxoplasma gondii Encephalitis from Mycophenolate Mofetil: A Case Report and Review
}

\author{
Singer JL ${ }^{1 *}$ and De La Pena $\mathrm{N}^{2}$ \\ ${ }^{1}$ Emergency Medicine, University of Pittsburgh Medical Center, Pittsburgh, USA \\ ${ }^{2}$ Infectious Disease, University of Pittsburgh Medical Center, Pittsburgh, USA \\ ${ }^{*}$ Corresponding author: Jordan L Singer, Emergency Medicine, University of Pittsburgh Medical Center, Pittsburgh, USA, Tel: 412-647-8283; E- \\ mail: singerjl2@upmc.edu
}

Received date: August 14, 2018; Accepted date: September 29, 2018; Published date: October 03, 2018

Citation: Singer JL, De La Pena N (2018) Toxoplasma gondii Encephalitis from Mycophenolate Mofetil: A Case Report and Review. Arch Med Vol No:10 Iss No:5:5

Copyright: (C2018 Singer JL, et al. This is an open-access article distributed under the terms of the Creative Commons Attribution License, which permits unrestricted use, distribution, and reproduction in any medium, provided the original author and source are credited.

\section{Abstract}

Mycophenolate mofetil (MMF) is often used in the treatment of autoimmune diseases such as myasthenia gravis and the prevention of organ rejection after transplantation. Toxoplasma encephalitis (TE) is typically associated with human immunodeficiency virus (HIV) infection. We present a case of an HIV sero-negative woman who developed TE after long-term MMF therapy for the treatment of myasthenia gravis. TE can occur even with low doses of MMF. A high index of suspicion is needed for patients presenting with focal neurologic deficits given poor outcomes in the majority of reported cases. Prophylaxis against TE can be considered although further study is needed.

Keywords: Toxoplasma encephalitis; Mycophenolate mofetil; Myasthenia gravis

\section{Abbreviations:}

AIDS: Acquired Immunodeficiency Syndrome; CSF: Cerebral Spinal Fluid; CT: Computed Tomography; HIV: Human Immunodeficiency Virus; IG: Immunoglobulin; IMPDH: Inosine Monophosphate Dehydrogenase; MMF: Mycophenolate Mofetil; MPA: Mycophenolic Acid; MRI: Magnetic Resonance Imaging; PCR: Polymerase Chain Reaction; TE: Toxoplasma Encephalitis; T. gondii: Toxoplasma gondii

\section{Introduction}

Mycophenolate mofetil (MMF) is an immunosuppressant often used in the treatment of autoimmune diseases such as myasthenia gravis and in the prevention of organ rejection after transplantation [1-5]. Toxoplasma gondii encephalitis (TE) is most often associated with human immunodeficiency virus (HIV) infection and acquired immunodeficiency syndrome (AIDS) with very few reported cases being connected with
MMF [6]. We present a case of a HIV sero-negative woman who developed TE after long-term MMF therapy for the treatment of myasthenia gravis.

\section{Case}

A 70-year-old female with history of Turner syndrome with severe cognitive impairment and myasthenia gravis diagnosed 10 years prior who was taking pyridostigmine, MMF $500 \mathrm{mg}$ twice daily and prednisone $\mathbf{2 0}$ mg every other day presented in status epilepticus. Patient had remote history of seizures as a child but was not on antiepileptic medications. She also had significant exposures to cats. Initial computed tomography (CT) head without contrast showed multiple lesions with surrounding vasogenic edema initially most concerning for metastatic cancer. Her exam was notable for decreased movement on her left side and somnolence. Magnetic resonance imaging (MRI) brain showed multiple ringenhancing lesions involving every lobe of brain, deep brain structures and cerebellum. CT chest, abdomen and pelvis were unremarkable. Cerebral spinal fluid (CSF) analysis revealed mild lymphocytic pleocytosis (32 White blood cells $/ \mathrm{mm}^{3}$, lymphocytes $87 \%$ ), elevated protein at 109 and mild decrease in glucose with CSF level of $89 \mathrm{mg} / \mathrm{dL}$ given the serum level was $200 \mathrm{mg} / \mathrm{dL}$. Serum Toxoplasma gondii (T. gondii) immunoglobulin (Ig) $\mathrm{G}$ was positive and T. gondii IgM was negative. Cerebral toxoplasmosis was confirmed with CSF $T$. gondii PCR that was positive. Serum HIV test was negative. CD4 count was 113 (normal 441-2156 cells $/ \mathrm{mm}^{3}$ ). The following CSF studies were negative: Cryptococcal antigen, Epstein-Barr virus polymerase chain reaction (PCR), herpes simplex virus $1 \mathrm{PCR}$, herpes simplex $2 \mathrm{PCR}$, bacterial gram stain, bacterial culture, and fungal culture. Patient's respiratory secretions tested positive for either rhinovirus or enterovirus, however the lab could not distinguish which. MMF was discontinued and she was treated with clindamycin $600 \mathrm{mg} 4$ times per day due to her sulfa allergy, as well as pyrimethamine $50 \mathrm{mg}$ daily and leucovorin $20 \mathrm{mg}$ daily. Patient improved mildy when seen at her one month follow up but had persistent left sided facial droop and left sided weakness. 
Repeat MRI brain showed interval decrease in the lesions and reduction in edema. Patient remained off of MMF and after six weeks was transitioned to maintenance therapy of $750 \mathrm{mg}$ atovaquone twice a day, clindamycin was discontinued, pyrimethamine was decreased to $25 \mathrm{mg}$ daily and leucovorin was decreased to $10 \mathrm{mg}$ daily.

\section{Discussion}

MMF is an immunosuppressant used in the treatment of various autoimmune conditions including myasthenia gravis, polymyositis, lupus nephritis, pemphigus, and bullous pemphagoid [1-3], as well as in the prevention of rejection after organ transplant including kidney and liver transplants $[4,5]$. MMF is the ester prodrug of mycophenolic acid (MPA), the active metabolite that functions as an immunosuppressant [7]. MPA inhibits the inosine monophosphate dehydrogenase (IMPDH), which suppresses de novo guanosine synthesis leading to decreased cell proliferation. MPA functions as a immunosuppressant by specifically inhibiting the type II isoform of IMPDH, which is primarily expressed in T and B lymphocytes, while not inhibiting the type 1 isoform of IMPDH found in most other cells. MMF is often selected for an immunosuppressant regimen due to it often being well tolerated given its favorable side effect profile when compared to other immunosuppressant [8].

Cerebral toxoplasmosis is often associated with reactivation of a latent infection due to immunodeficiency such as AIDS or secondary to immunosuppressive therapy [6].

The clinical manifestation of cerebral toxoplasmosis is often a sub-acute gradual process and symptoms include mental status changes, seizures, focal motor deficits, cranial nerve disturbances, sensory changes, cerebellar signs, movement disorders and neuropsychiatric findings. Clinical manifestations of non-cerebral toxoplasmosis include fever, malaise, ocular disease, lymphadenopathy and more rarely myocarditis, polymyosistis, pneumonitis, and hepatitis [9]. Risk factors for infection include exposure to certain raw or undercooked foods as well as exposure to kittens [10]. Studies have shown that toxoplasmosis seroprevalence range from $4 \%-92 \%$ worldwide and recent estimates show a rate of $22.5 \%$ in the United States $[6,11,12]$, which is relevant given that cerebral toxoplasmosis is secondary to reactivation of latent infection. Diagnosis is typically made indirectly, with serology, or directly, with techniques such as polymerase chain reaction looking for T. gondii DNA [9]. Immunosuppressant implicated in the development of cerebral toxoplasmosis includes cyclosporine, azathioprine, tacrolimus, and methylprednisolone [13-16] as well as rituximab [17,18], infliximab [19], fingolimod [20] and adalimumab [21]. First-line treatment includes a combination of pyrimethamine, leucovorin and sulfadiazine. Clindamycin is typically used as an alternative for sulfadiazine in those hypersensitive to sulfa drugs, although there are other options that have been less studied [9]. Despite treatment, mortality in patients with TE that is not secondary to AIDS has been reported as high as 50\% [15].

There are only four total cases of TE reported in the literature that involve HIV-seronegative patients taking MMF [22-24]. These cases, as well as ours, are summarized in Table 1. The patient in our case presented with sub-acute mental status changes, unilateral motor deficits and seizures without evidence of extra-central nervous system manifestations of disseminated toxoplasmosis or constitutional symptoms, such as fever. One of the four previously reported cases had a more progressive and chronic onset with the remaining three being more acute. Fever was only reported in two of the previous cases while focal neurologic findings were found in all cases including ours. Our case was the only one that reported seizures. CT and MRI findings for all the cases, including ours, showed multiple ring-enhancing lesions at some point with four of the five showing them at presentation. CSF analysis on all the patients was not consistent with meningitis; however, there was more of a pleocytosis in our case than in the previously reported cases. Diagnosis of TE was made with CSF PCR in two of the previous cases as well as in our case, while the other two diagnoses were confirmed with brain biopsy. In summary, HIV seronegative patients with TE seem to present primarily with focal neurologic deficits and have multiple ring enhancing lesions on imaging, while constitutional symptoms and acuity can vary.

Table 1: All reported cases of TE that involve HIV-seronegative patients taking MMF.

\begin{tabular}{|c|c|c|c|c|c|}
\hline Case report & $\begin{array}{l}\text { Age } \\
\text { (years) }\end{array}$ & Gender & $\begin{array}{l}\text { Immunosuppression } \\
\text { regimen }\end{array}$ & Disease & Outcome \\
\hline \multirow[b]{2}{*}{$\begin{array}{l}\text { Bernardo et al. } \\
\text { [22] }\end{array}$} & 77 & Male & $\begin{array}{l}\text { Prednisone } 20 \text { mg qod } \\
\text { MMF } 1500 \mathrm{mg} \mathrm{qd}\end{array}$ & Myasthenia gravis & Died 2 months after symptom onset \\
\hline & 72 & Female & $\begin{array}{l}\text { MMF } 1500 \text { mg BID } \\
\text { Prednisone } 10 \text { mg qd } \\
\text { Rituximab } 1000 \text { mga }\end{array}$ & Inflammatory myopathy & Died 2 months after symptom onset \\
\hline $\begin{array}{l}\text { Pistacchi et al. } \\
\text { [23] }\end{array}$ & 48 & Female & $\begin{array}{l}\text { MMF } 1000 \text { mg BID } \\
\text { Prednisone } 50 \text { mg qd }\end{array}$ & $\begin{array}{l}\text { Undifferentiated connective } \\
\text { tissue disease }\end{array}$ & Died 2 weeks after presenting \\
\hline $\begin{array}{l}\text { Sasson et al. } \\
{[24]}\end{array}$ & 54 & Female & $\begin{array}{l}\text { MMF } 1000 \text { mg BID } \\
\text { Prednisolone } 12 \text { mg qod } \\
\text { IVIG qmonthly. } 4 \text { mg/kg }\end{array}$ & Myasthenia gravis, TWI & $\begin{array}{l}\text { Alive at time of publication with interval decrease in } \\
\text { brain lesion sizes }\end{array}$ \\
\hline
\end{tabular}




\begin{tabular}{|l|c|c|c|c|}
\hline Our case & 70 & Female & $\begin{array}{l}\text { MMF } 500 \text { mg BID } \\
\text { Prednisone qod }\end{array}$ & Alive 2 months after symptom onset with interval \\
decrease in brain lesion sizes
\end{tabular}
$\begin{aligned} & \text { Note=IVIG: intravenous immunoglobulin; qod: once every other day; qd: once daily; BID: twice daily; qmonthly: once a month } \\
& \text { a - Received } 2 \text { doses } 8 \text { weeks prior to presentation }\end{aligned}$

The typical dose of MMF used in clinical trials was $1000 \mathrm{mg}$ twice daily with the range being between 1000 and $3000 \mathrm{mg}$ per day [25]. Our patient received a total of $1000 \mathrm{mg}$ of MMF each day, which was less than the patients in the previous cases whose doses ranged from 1500-3000 mg each day [22-24]. The only other immunosuppressant our patient was exposed to was an oral corticosteroid, which was a similar dose to that which was used in the previous cases. Two of the previously reported cases involved patients with further immunosuppression with one patient having received two doses of rituximab eight months before presenting and another having received monthly intravenous immunoglobulin infusions. The absolute CD4+ T-cell level in our patient was low as in two of the three previous cases that reported this level. This shows that TE is possible even low doses of MMF.

The patient in our case unfortunately did not any significant neurologic improvement with treatment and unfortunately remained below her baseline level of mental functioning. Of the four previously reported cases, survival was not good with one patient dying within 2 weeks of presentation and two patients dying two months after diagnosis. The last case described a patient with progressive lesions initially but with stable disease at the time of publication. Unfortunately, the prognosis seems to be poor with these cases having a similar mortality rate to the $50 \%$ that is described in the literature [15]

Our case report shows that TE can occur even with doses of MMF at the low end of the therapeutic range. Given the poor prognosis in these patients, providers should have a high index of suspicion for patients who present with focal neurologic deficits and should consider early imaging with CT and MRI. A previous paper mentioned considering prophylaxis with trimethoprim/sulfamethoxazole (TMP-SMX) for high-risk individuals such as those taking 3 grams per day of MMF [22]. Given the high mortality of TE, prophylaxis can be considered for all patients taking MMF given TE can occur even at low doses. The benefits of this protection would need to be balanced with the side effects of long term TMP-SMX use. Further studies on this may be necessary.

\section{Funding}

There was no source of funding.

\section{Conflicts of Interest}

Drs. Jordan L Singer and Nicolas De La Pena have no conflicts of interest of financial ties to disclose. No funding was used for this study.

\section{References}

1. Schneider C, Gold R, Reiners K, Toyka KV (2001) Mycophenolate mofetil in the therapy of severe myasthenia gravis. Eur Neurol 46: 79-82.

2. Feng L, Deng J, Huo DM, Wu QY, Liao YH (2013) Mycophenolate mofetil versus azathioprine as maintenance therapy for lupus nephritis: A meta-analysis. Nephrology (Carlton). 18: 104-110.

3. Eskin-Schwartz M, David M, Mimouni D (2012) Mycophenolate mofetil for the management of autoimmune bullous diseases. Immunol Allergy Clin North Am 32: 309-315.

4. Maripuri S, Kasiske BL (2014) The role of mycophenolate mofetil in kidney transplantation revisited. Transplant Rev (Orlando) 28: 26-31.

5. Kaltenborn A, Schrem H (2015) Mycophenolate mofetil in liver transplantation: A review. Ann Transplant 18: 685-696.

6. Saadatnia G, Golkar M (2012) A review on human toxoplasmosis. Scand J Infect Dis 44: 805-814.

7. Ritter ML, Pirofski L (2009) Mycophenolate mofetil: Effects on cellular immune subsets, infectious complications, and antimicrobial activity. Transpl Infect Dis 11: 290-297.

8. Zwerner J, Fiorentino D (2007) Mycophenolate mofetil. Dermatol Ther 20: 229-238.

9. Montoya JG, Liesenfeld O (2004) Toxoplasmosis. Lancet 363: 1965-1976.

10. Jones JL, Dargelas V, Roberts J, Press C, Remington JS, et al. (2009) Risk factors for Toxoplasma gondii infection in the United States. Clin Infect Dis 49: 878-884.

11. Wyrosdick HM, Schaefer JJ (2015) Toxoplasma gondii: History and diagnostic test development. Anim Health Res Rev 16: 150-162.

12. Zhang K, Lin G, Han Y, Li J (2016) Serological diagnosis of toxoplasmosis and standardization. Clin Chim Acta 461: 83-89.

13. Gallino A, Maggiorini M, Kiowski W, Martin X, Wunderli W, et al. (1996) Toxoplasmosis in heart transplant recipients. Eur J Clin Microbiol Infect Dis 15: 389-393.

14. Renoult E, Georges E, Biava MF, Hulin C, Frimat L, et al. (1997) Toxoplasmosis in kidney transplant recipients: Report of six cases and review. Clin Infect Dis 24: 625-634.

15. Martina MN, Cervera C, Esforzado N, Linares L, Torregrosa V, et al. (2011) Toxoplasma gondii primary infection in renal transplant recipients. Two case reports and literature review. Transpl Int 24: 6-12.

16. Mele A, Paterson PJ, Prentice HG, Leoni P, Kibbler CC (2002) Toxoplasmosis in bone marrow transplantation: A report of two cases and systematic review of the literature. Bone Marrow Transplant 29: 691-698.

17. Safa G, Darrieux L (2013) Cerebral toxoplasmosis after rituximab therapy. JAMA Intern Med 173: 924-926. 
18. Savsek L, Opaskar TR (2016) Cerebral toxoplasmosis in a diffuse large B cell lymphoma patient. Radiol Oncol 50: 87-93.

19. Young JD, McGwire BS (2005) Infliximab and reactivation of cerebral toxoplasmosis. N Engl J Med 353: 1530-1531.

20. Enriquez-Marulanda A, Valderrama-Chaparro J, Parrado L, Vélez JD, Granados AM, et al. (2017) Cerebral toxoplasmosis in an MS patient receiving Fingolimod. Mult Scler Relat Disord 18: 106-108.

21. Nardone R, Zuccoli G, Brigo F, Trinka E, Golaszewski S (2014) Cerebral toxoplasmosis following adalimumab treatment in rheumatoid arthritis. Rheumatology (Oxford) 53: 284.

22. Bernardo JR, Chahin N (2015) Toxoplasmic encephalitis during mycophenolate mofetil immunotherapy of neuromuscular disease. Neurol Neuroimmunol Neuroinflamm 2: 63.
23. Pistacchi $M$, Gioulis $M$, Zirillo $M$, Francavilla $E$, Zambito $M S$ (2016) Cerebral toxoplasmosis in undifferentiated connective disease treated with mycophenolate mofetil: An unusual case report. Acta Neurol Belg 116: 633-636.

24. Sasson SC, Davies S, Chan R, Davies L, Garsia R (2016) Cerebral toxoplasmosis in a patient with myasthenia gravis and thymoma with immunodeficiency/Good's syndrome: a case report. BMC Infect Dis 16: 457.

25. Cahoon WD Jr, Kockler DR (2006) Mycophenolate mofetil treatment of myasthenia gravis. Ann Pharmacother 40: 295-298. 